\title{
Systematic Biases in Cloud-Track-Wind Data from Jet-Stream Regions
}

\author{
By Per Kållberg* \\ Swedish Meteorological and Hydrological Institute, S-601 76 Norrköping, Sweden
}

Frédéric Delsol

ECMWF, Shinfield Park, Reading, RG2 9AX, U.K. (Manuscript received 30 October 1986, in revised from 1 February 1987)

\begin{abstract}
Cloud-track-wind data, also often called SATOB data, provide an invaluable source of observational information from otherwise sparsely covered parts of the lower and upper troposphere, particularly in the tropics. SATOB data were, for the first time, collected on a global basis during FGGE. During the analysis of these data for the ECMWF Main level III-b production, some questions arose regarding apparent systematic biases in the data in and near jetstreams. In preparation for a reassimilation of parts of the FGGE at ECMWF these questions were adressed again, benefitting from the accumulated experience of global data assimilation at the Centre. Several types of diagnostics, based both on the data assimilation scheme and independent, collocated observations were extracted and evaluated, based on the Final FGGE level II-b data from December 1978.

The biases were found to be negative, underestimating the windspeed, and quite systematic. All datasets from different producers that could be reliably assessed were found to suffer. The problem was most pronounced in the subtropical jetstreams, where individual wind analyses were found to be seriously deformed by too weak SATOB windspeeds, especially in areas void of other sources of data. Impact was also seen in monthly averages. In a simple calibration experiment, an attempt was made to reduce the biases. The result showed a great impact of the calibration, indicating both the importance of SATOB data and the risks associated with their systematic biases.
\end{abstract}

\section{Introduction}

Cloud track wind data (often called SATOB) collected from five geostationary satellites during FGGE gave, for the first time, a good coverage of tropical and subtropical wind observations at all longitudes. When the ECMWF assimiliation of the Main FGGE level IIB data started in 1979, our knowledge of the quality and performance of the SATOB data was very limited. It was recognized, however, that a possible source of error in the data

* Visiting scientist at ECMWF 1985. was the assigned height. The methods of height assignment varied between different producers, some giving a cloud (top) temperature with a corresponding pressure determined from some (climatological) temperature profile, while others only provided a pressure level. Assuming that temperature measurements, when available, were more reliable than assigned pressure levels, ECMWF adopted a scheme for reassignment of upper troposphere cloud wind heights to the level of best fit between reported cloud temperature and the 6 hour first guess forecast temperature. A small collocation study by $\mathrm{P}$. Julian and M. 
Kanamitsu at ECMWF (not published) showed some improvement in RMS differences between collocated radiosonde and SATOB data after the height reassignment. During the level IIIb assimilation, the effect of the height reassignment was not evaluated in detail, although statistics from individual analyses showed that the height changes were usually of the order $30-40 \mathrm{hPa}$ or less. The forecast error correlation used for the ECMWF Main level IIIb assimilation was very wide in the vertical, making the net effect of the height reassignment small. In Baede et al. (1985) the consequences of the use of broad vertical structure function is discussed in connection with an observing system experiment concerned with aircraft data. Julian (1980) also pointed out the difficulties in analyzing sharp vertical gradients of the horizontal wind in divergent areas near cloud tops in the tropical convergence zone with these structure functions.

An observing system experiment specifically studying the impact of the FGGE SATOB data was carried out at ECMWF by Kållberg et al. (1982). It was shown that the cloud wind data had a positive impact on the analyzed tropical motion, while their impact at higher latitudes was rather questionable and sometimes even negative, particularly in the subtropical jetstream. Large and systematic negative biases were found in the reported zonal wind components, especially over the Mediterranean-Western Asia region. The problems were connected with high level cirrus over mountaineous regions not being representative of the flow.

An enhanced set of FGGE observations, the final IIb set, has now become available. In this set, several subsets of SATOB data have been added or replaced. The coverage over the western Pacific ocean is particularly upgraded due to a large set of vectors extracted from Himawari imagery by the SSEC, Space Science and Engineering Center, University of Wisconsin. In addition to the enhanced observational data base, the ECMWF assimilation system has, since the Main IIIb analysis in 1980-81, been upgraded in many respects. The major changes in the assimila- tion scheme of 1985 compared to that used for the Main IIIb analyses are

(a) improved vertical interpolations between the vertical grids used in the analysis and forecast model

(b) improved data selection and quality control algorithms (see Shaw et al. 1984)

(c) improved statistical structure functions for the optimum interpolation (see Hollingsworth and Lönnberg, and Lönnberg and Hollingsworth, 1986)

(d) diabatic, rather than adiabatic, non-linear normal mode initialization

(e) a new, spectral T63 forecast model.

The substantial enhancements of both the observational dataset and the data assimilation system made a re-analysis of at least some periods of the FGGE data seem worthwhile. ECMWF hence decided to reanalyse the two Special Observing Periods (SOPs). Also, during the production of the Main level IIIb analyses, December 1978 was used as a running-in period. Many errors and inconsistencies were discovered and corrected for, but the overall quality of the Main December assimilation may be considered as poor. For the reruns, December was again used as a test- bench for the new assimilation system and the enhanced data. An overall description of the rerun system can be found in Uppala (1986).

During the evaluation of the December reanalyses, the SATOB bias problem proved to be serious. The increased amount of data, and the revised first guess error statistics combined in giving analyses that in som areas were, to say the least, suspicious. This demonstrated in section 2, where examples both from FGGE and from 1986 are presented. As a possible remedy, a simple calibration of the data was attempted. Obviously any calibration of observational data is highly controversial, and the experiments presented in section 3 should be considered mainly as a sensitivity test, that further demonstrates the problem of biased SATOB data. In the conclusion, section 4 , the decision taken at ECMWF regarding the use of the cloud track wind data for the two SOPs is motivated, 
and its effect on the Final IIIb analyses is discussed.

\section{Symptoms of bias}

For the reassimiation of the December data it was decided to remove the height reassignment algorithm used for the Main analysis. Also, based on experience from observing system experiments, SATOB data were not used over land.

The use of the SATOB data, exactly as given by the producers, gave us the opportunity to study the quality of the data unaffected by our modifications. Indeed, after the conclusion of the December analyses we were informed (D. Wylie, personal communication) that, for the University of Wisconsin data, the pressure level assignments should be considered as more reliable than the temperatures. Due to the importance of the Indian Ocean and Western Pacific Ocean SATOB data for the FGGE analyses, the best possible use of the University of Wisconsin data is particularly important, and during the assimilation the monitoring was concentrated on those areas. Only upper troposphere SATOB data are discussed in this report.

\subsection{A synoptic example}

On December 23, $00 \mathrm{GMT}$, large analysis increments were noted in the $250 \mathrm{hPa}$ wind analyses east of Japan. The first guess forecast showed a jet stream maximum with a smooth elongated shape and a maximum windspeed exceeding $75 \mathrm{~ms}^{-1}$ between $138^{\circ} \mathrm{E}$ and $155^{\circ} \mathrm{E}$ (Fig. 1); while the analysis has a wind speed maximum less than $45 \mathrm{~ms}^{-1}$ around $152^{\circ} \mathrm{E}$ (Fig. 2). The area is well covered by SATOB data from Himawari produced by the Japanese Centre (HI JA) and SSEC, University of Wisconsin (HI WI). Aircraft data (CI 7, CO664, JL77, JL75) and radiosonde data (C7T, EREH, 47678) both give observed windspeeds that agree well with the first guess, while the SATOB data underestimate the windsweed. Compare, for instance, the AIREP from CI 7 at $\left(150^{\circ} \mathrm{E}, 32^{\circ} \mathrm{N}\right)$ which gives $75 \mathrm{~ms}^{-1}$ with the HI WI SATOB at $\left(152^{\circ} \mathrm{E}, 32^{\circ} \mathrm{N}\right)$ giving $35 \mathrm{~ms}^{-1}$. Both cannot be correct, even allowing for the differences in given pressures and

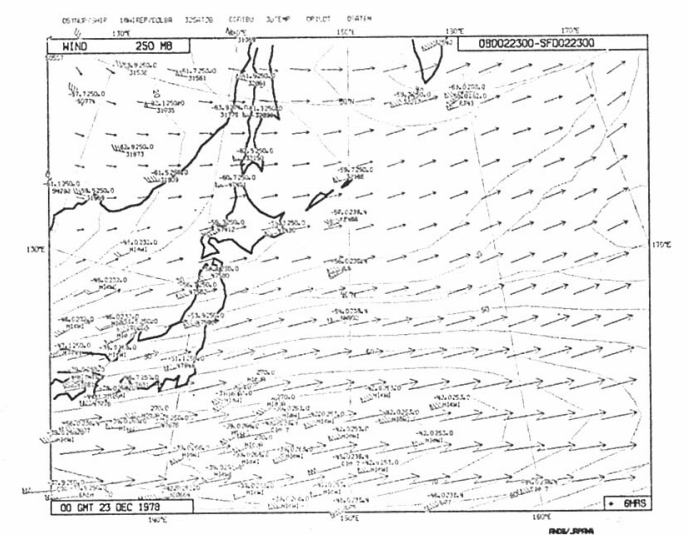

Fig. 1 First guess forecast of $250 \mathrm{hPa}$ winds at 00 GMT, 23 Dec. 1978. Isotachs (dotted) are in $\mathrm{ms}^{-1}$. Observations from $\pm 50 \mathrm{hPa}$ interval are plotted. HI WI and HI JA are Himawari SATOB data, 5-digit numbers (and EREH) indicate TEMP data. Other data are AIREPs. Observed (or assigned) temperatures, in ${ }^{\circ} \mathrm{C}$, and pressures, in $\mathrm{hPa}$, are plotted at each observation.

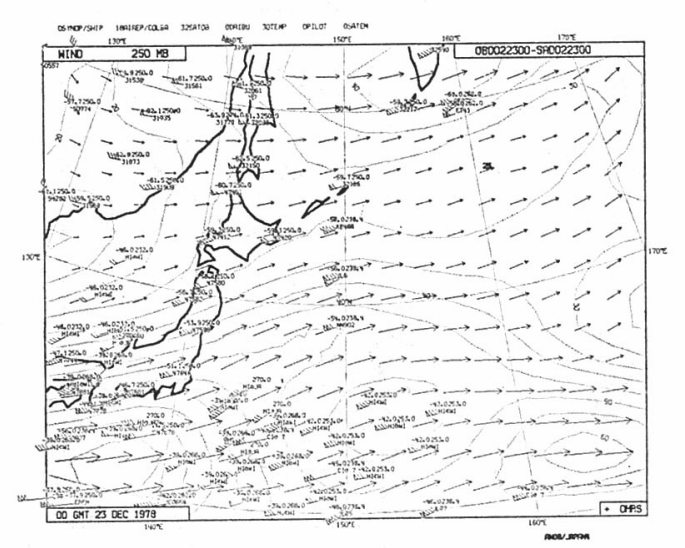

Fig. 2 As Fig. 1, but for uninitialized analysis 00 GMT, 23 Dec. 1978.

temperatures. Many cases of similar discrepancies between SATOB data and other data were noted during the assimiation. The areas most affected were in the western Pacific jetstream and the subtropical jet over western and central Asia.

\subsection{Average analysis increments}

From a set of 104 analyses and first guess fields from 26 days in December 1978, gridpoint by gridpoint values of the mean analysis increment, i.e. analysis minus first guess, and its standard deviation were calculated 


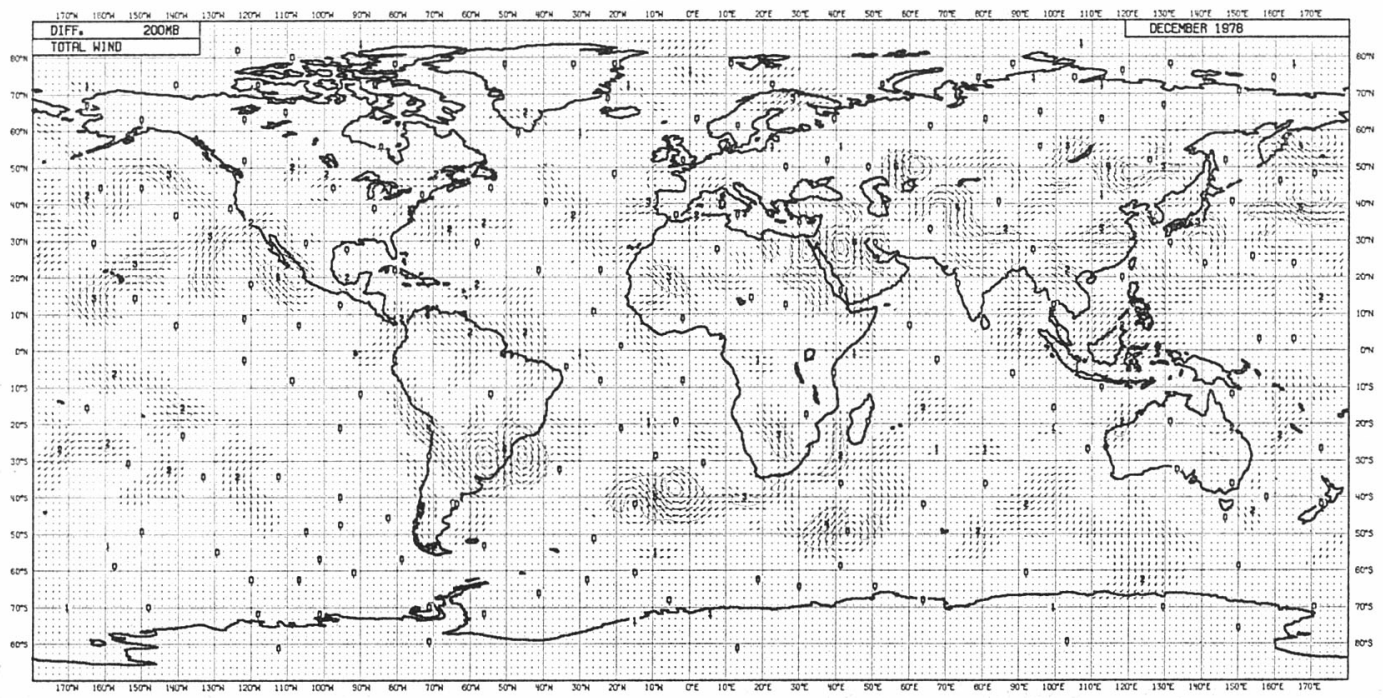

Fig. 3 Average wind analysis increment at $250 \mathrm{hPa}$ (analysis minus first guess) for 26 days in Dec 1978. Isotachs (dotted) for every $2.5 \mathrm{~ms}^{-1}$.

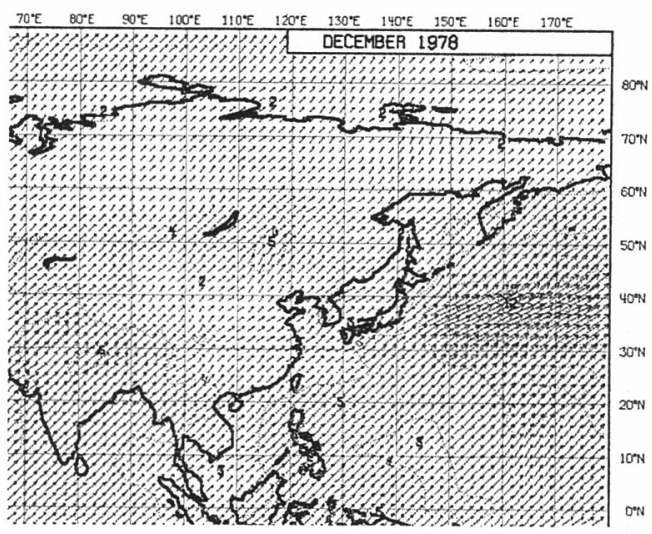

Fig. 4 Standard deviation (SD), gridpoint by gridpoint, of wind-components for 26 days in Dec 1978. $u$ - and $v$ - SD components are plotted as vectors; equal SD in both components corresponds to "SW" arrows. Note the anisotropic maximum of $12 \mathrm{~ms}^{-1}$, larger in $u$ than in $v$, east of Japan.

and mapped. In Figure 3 the mean wind increment at $200 \mathrm{hPa}$ is shown.

Several radiosonde stations show large biases, the most obvious are Gough Island $\left(40^{\circ} \mathrm{S}, 10^{\circ} \mathrm{W}\right)$, Marion Island $\left(40^{\circ} \mathrm{S}, 37^{\circ} \mathrm{E}\right)$, Isla Socorro $\left(18^{\circ} \mathrm{N}, 110^{\circ} \mathrm{W}\right)$, and a few stations in South America and western Asia. These biases are due to identified problems at the individual radiosonde stations.

Another area with large analysis incre- ments is however found east of Japan, where a monthly mean easterly analysis increment of $5 \mathrm{~ms}^{-1}$ stretches from $180^{\circ} \mathrm{E}$ to $150^{\circ} \mathrm{E}$ between $35^{\circ} \mathrm{N}$ and $40^{\circ} \mathrm{N}$. This is the area examined in the example above, where biased SATOB data were frequently found. The standard deviation of the analysis increment exceeds $12 \mathrm{~ms}^{-1}$ in this area, and is, contrary to other areas, not isotropic, but larger in the $u$-component than in the $v$-component (Fig. 4). The observed wind data are thus very far off from the first guess, and have a large impact on the wind analyses.

\subsection{First guess fit}

During the data assimilation, the fits of all accepted observations to the first guess forecast, the analysis and the initialized analysis are calculated and archived. These data provide a valuable source of information on the behaviour of the data assimilation system as well as on the quality of the observations. In particular the differences between observations and the first guess forecast, when averaged over a month, can reveal otherwise hard-to-discover systematic data problems. This is so since the quality of the first guess forecast is well known after several years of operations at ECMWF. Hollingsworth et al., (1985) discuss the value and the use of the 


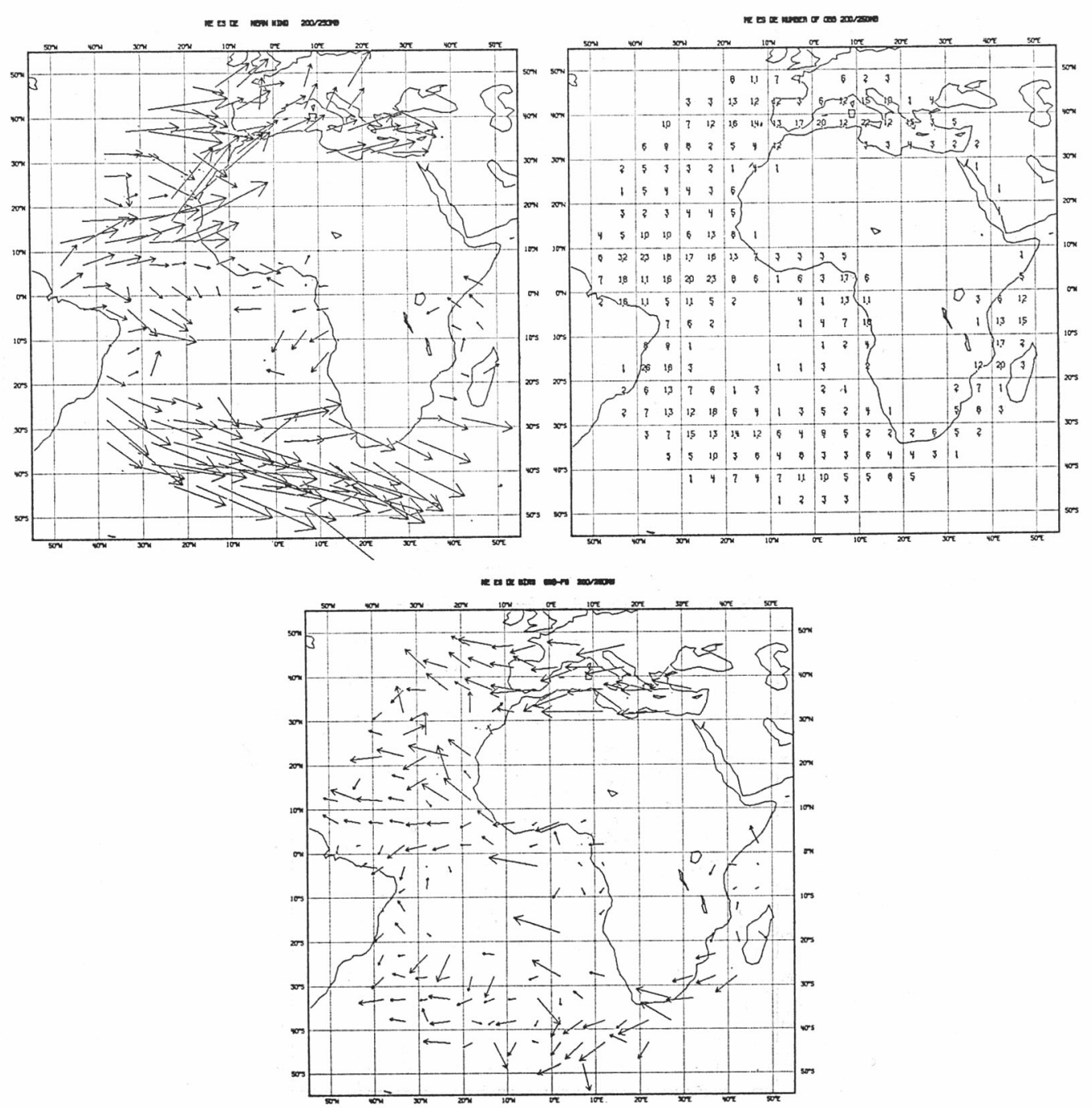

Fig. 5 Average of all SATOB data for Dec 1978 in $5^{\circ} \times 5^{\circ}$ boxes (top left). Number of data in each box (top right). Box average of observed minus first guess differences (bottom). The scale of the arrows is such that $10^{\circ}$ of longitude on the map corresponds to about $18 \mathrm{~ms}^{-1}$.

first guess fit statistics in some detail.

Aggregate statistics of observed minus first guess wind speed differences for observations between $100 \mathrm{hPa}$ and $300 \mathrm{hPa}$ are shown in Table 1 for all the SATOB producers available in December 1978. Statistics for ASDAR* and conventional AIREP data are also included. In the extratropics, all SATOB data show a negative bias in the $u$-component, varying between $-7.0 \mathrm{~ms}^{-1}$ for Himawari/ SSEC and $-1.6 \mathrm{~ms}^{-1}$ for GOES-E/NESS. The

* ASDAR are high quality wind reports determined automatically by the inertial navigation system of wide-bodied jet aircraft. aircraft data on the other hand show positive $u$-biases of $0.6 \mathrm{~ms}^{-1}$ for ASDAR and $0.8 \mathrm{~ms}^{-1}$ conventional AIREPs. The aircraft biases are probably due to the use of negatively biased SATOB data for the first guess forecasts. As a consequence of the weaker climatological means of the extratropical meridional wind, biases in the $v$-component generally have smaller values, although the relative error may still be of importance. This also applies to biases in the tropics.

The standard deviations of both components show significant differences between the datasets. The aircraft data, and particularly 


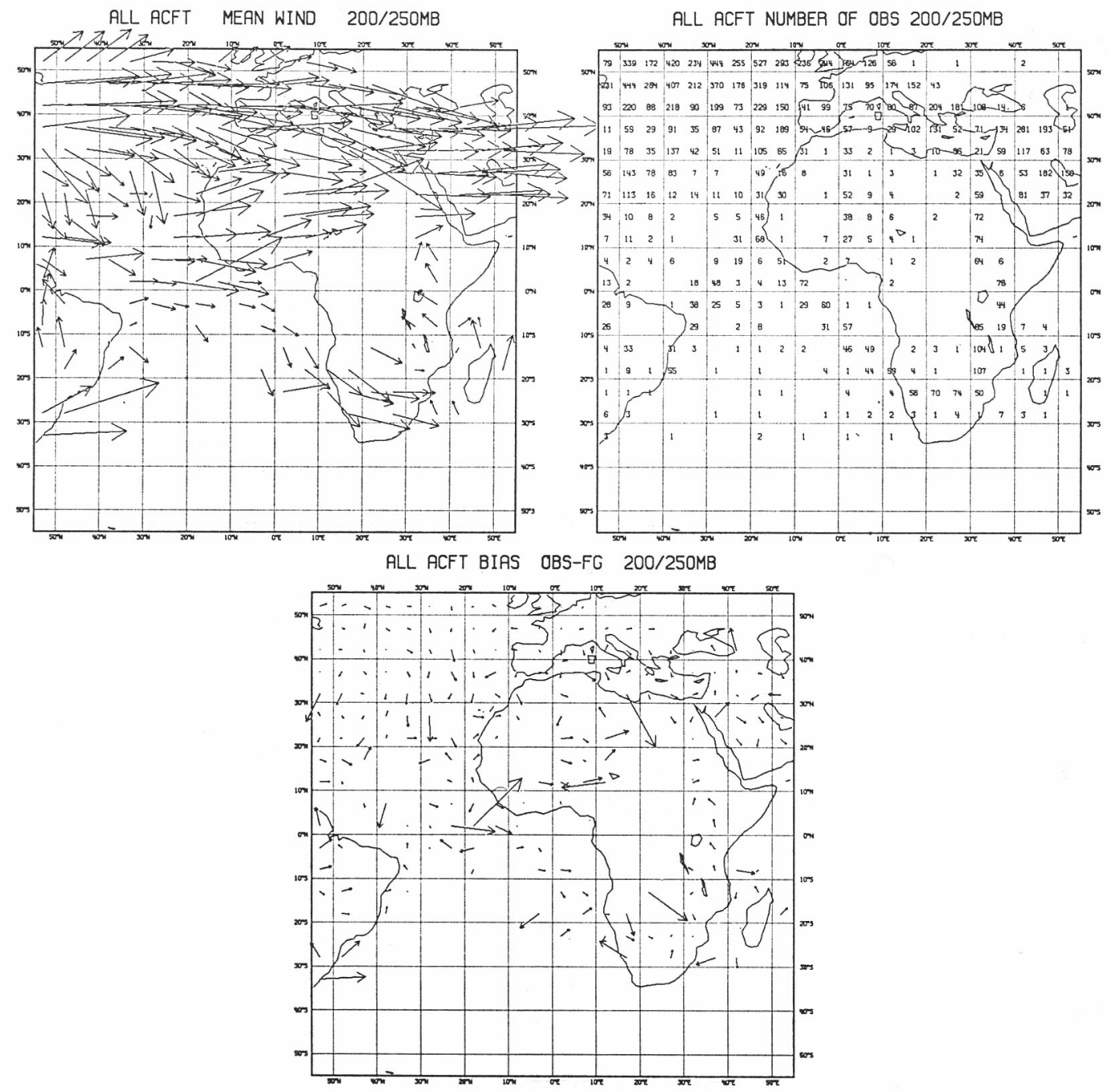

Fig. 6 As Fig. 5, but for aircraft data.

the ASDAR winds, seem to have an excellent quality, with standard deviations of $6.0 \mathrm{~ms}^{-1}$ and $7.5 \mathrm{~ms}^{-1}$ for the conventional AIREPs. The SATOB data exhibit much larger standard deviations, not only in the extratropical $u$ component, but also in all other components. From these simple statistics it is however not advisable to categorize the standard deviation further, they may be due to observational errors and/or representativity.

When evaluating the performance of data with varying positions, such as SATOB and aircraft data, they may be averaged geographically using the method of Delsol (1985), in order to show geographic variations. All
SATOB data used for the analysis at $200 \mathrm{hPa}$ and $250 \mathrm{hPa}$ are averaged for the month into $5^{\circ} \times 5^{\circ}$ boxes. The averaged SATOBs for December 1978 within a box, the number of SATOBs in each box, and the mean monthly box difference between the SATOBs and the first guess forecast are shown in Figure 5 for the Meteosat area. Large easterly biases, more than $10 \mathrm{~ms}^{-1}$ are found over the Mediterranean and over the South Atlantic. Corresponding maps for aircraft observations, Figure 6, show no zonal biases.

SATOB data from the University of Wisconsin (both Himawari and GOES-IO) and the Japanese Himawari producer show very similar 


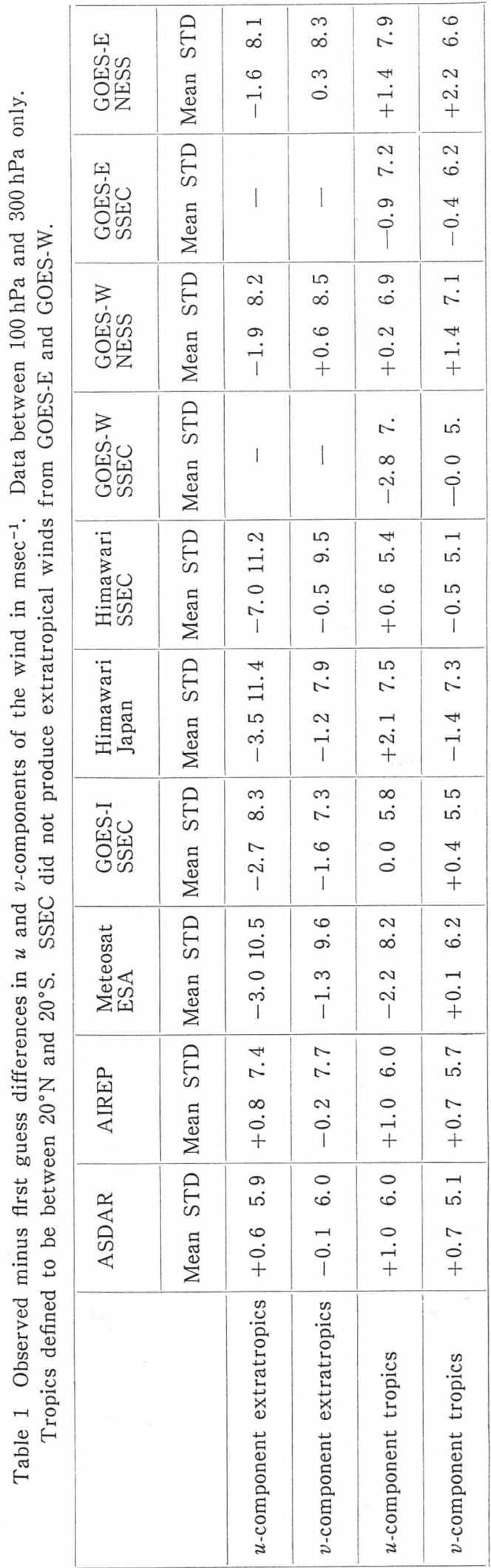

biases in their zonal speeds. Data produced by NESS, from GOES-E and GOES-W, on the other hand are much less biased. It must be pointed out, however, that the NESS data cover areas with few aircraft or TEMP/ PILOT data. This makes first guess comparisons less informative, even dangerous, since the forecast is to larger extent based on the same kind of SATOB data that are being checked. The Meteosat, GOES-IO and Himawari areas on the other hand are well covered with aircraft and TEMP/PILOT observations, making the first guess less dependent on the SATOB data.

The biases displayed in Table 1 and Figure 5 and 6 were all for FGGE data from December 1978. For a couple of years, however, ECMWF has been monitoring daily routine observations on an operational basis (Delsol, 1985). The monitoring indicates that SATOB biases in upper troposphere jetstream areas are still prevalent. An example is seen in Figure 7 which shows similar $5^{\circ} \times 5^{\circ}$, monthly averages for May 1986. We select to show only two areas where independent Aircraft and Temp/Pilot data are readily available for comparison; the northern part of the Meteosat area, and the southern part of the Himawari area. For the area covered by GOES, centered around $130^{\circ} \mathrm{W}$, the bias is less significant, but clearly present. As during the FGGE very few independent data are available for comparisons. It has been noted, however, that zonal kinetic energies in the ECMWF analyses over the GOES area have a diurnal period, caused by the alternation between analyses based on SATOB data at some analysis periods, and aircraft data at others. SATOB data are not produced every 6 hour period, and the aircraft data amount has a diurnal frequency due to airline schedules.

\subsection{Collocation statistics}

Any evaluation of an observing system using analyzed, or first guess forecast fields is affected by the assimilation system used. To eliminate the influence of the system, a collocation study was also carried out on the December 1978 data.

All collocated pairs of wind observations 

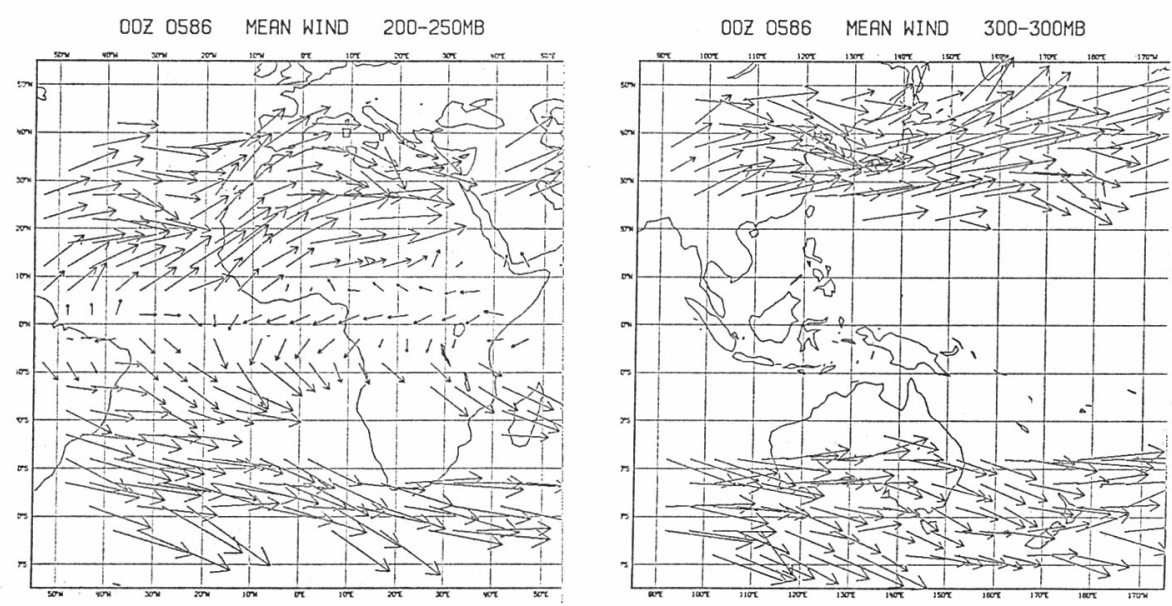

OOZ 0586 BIAS OBS-FG 200-250MB

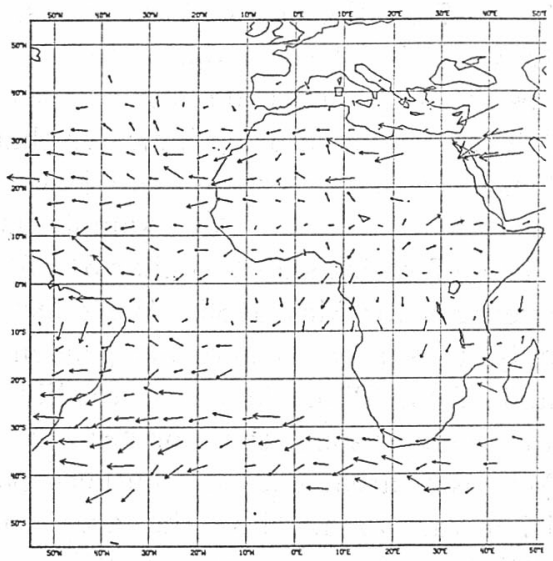

OOZ 0586 BIAS OBS-FG 300-300MB

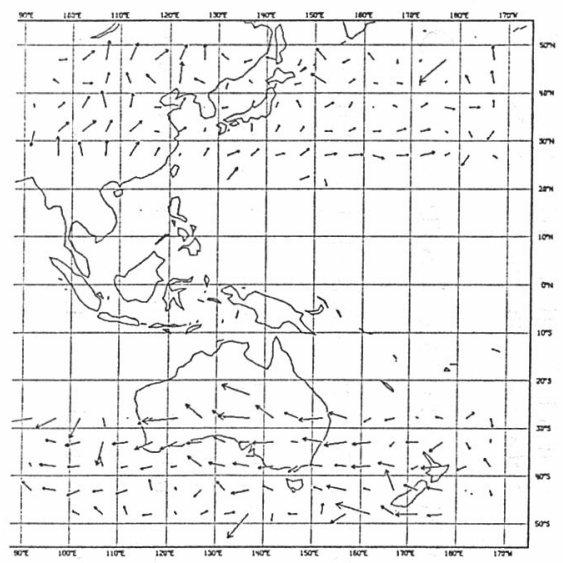

AOZ 0586 BIAS OBS-FG 200-250MB

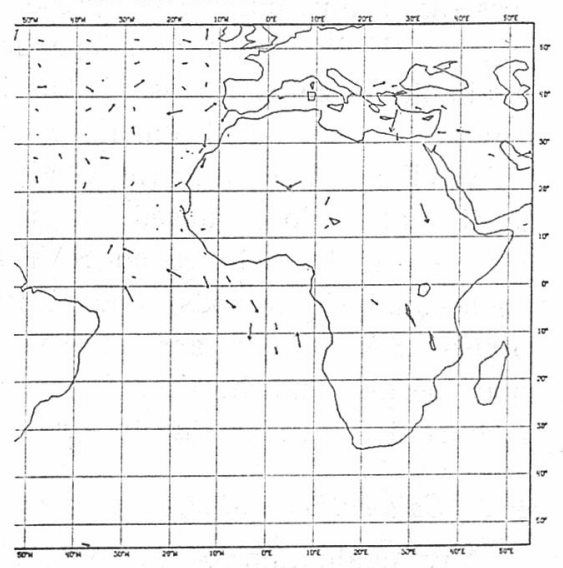

POŻ 0586 BIAS OBS-FG $300-300 \mathrm{MB}$

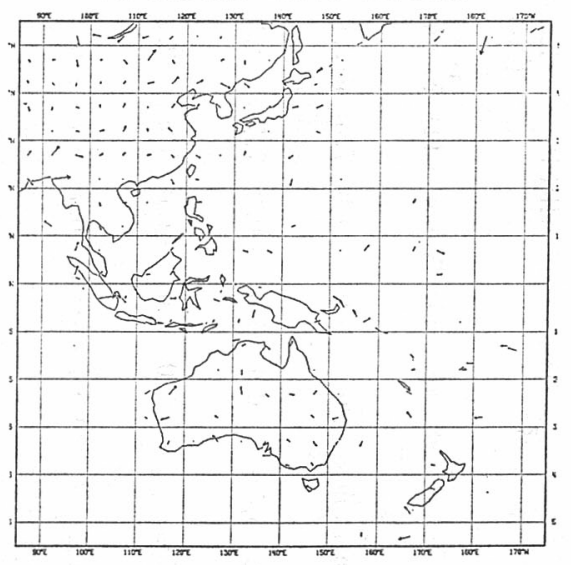

Fig. $75^{\circ} \times 5^{\circ}$ monthly average SATOB observation (top), difference SATOB-first guess (middle), difference Aircraft-first guess (bottom left) difference TEMP/PILOT-first guess (bottom right), $200-250 \mathrm{hPa}$ for the African area (left), $300 \mathrm{hPa}$ for the Australian area (right). 
from SATOB, AIREP/ASDAR and TEMP/ PILOT with great circle distances from each other less than a cut-off separation were extracted from the IIb database. The pairs could then, in the statistical treatment, be stratified depending on time separation, latitude, pressure interval and pressure separation. Scatterograms were produced for reported windspeed (disregarding direction), reported direction, as well as SATOB wind component parallel and normal to that of the aircraft or TEMP/PILOT. The results for the total windspeed of SATOB/TEMP/PILOT data poleward of $20^{\circ} \mathrm{N} / \mathrm{S}$ are shown in Figure 8 for the different producers. In the table accompanying the figure the mean and standard deviations are shown, as well as the correlation; a linear regression line is also shown in the figure. The time window was \pm 3 hours from the synoptic times, the hor- a)

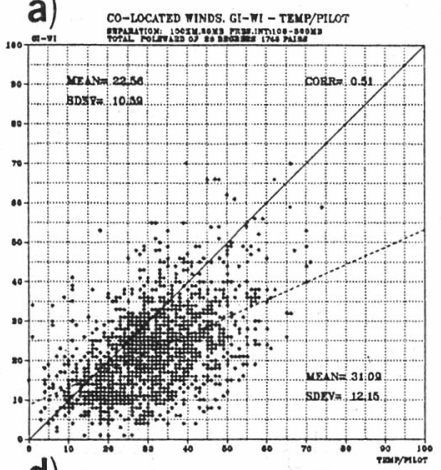

d) CO-LOCATED WINDS. GT-NE-TEMP/PROT

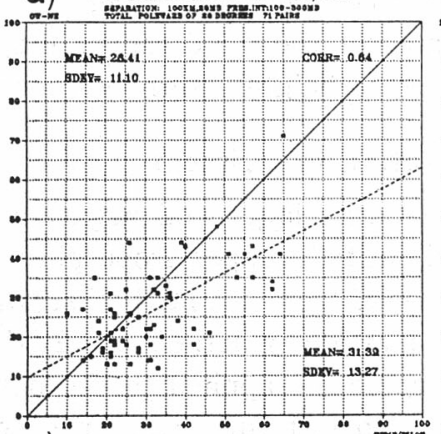

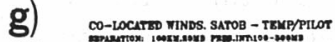

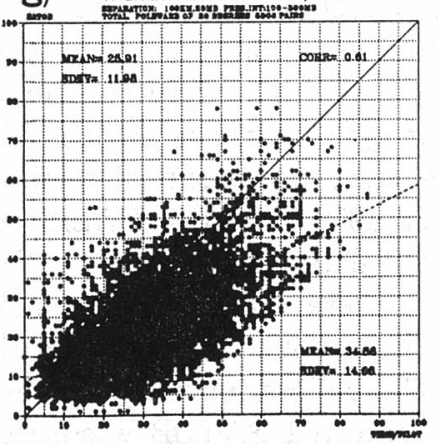

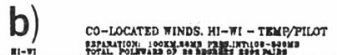

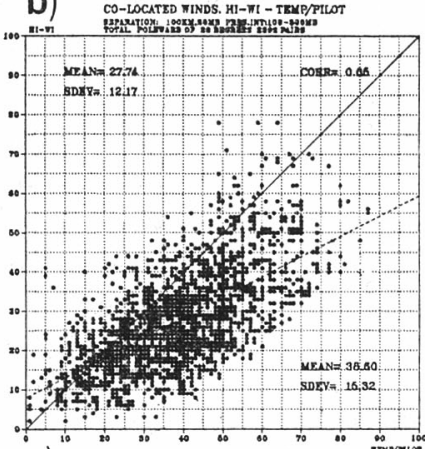

e) CO-LOCATED TINDS. GE-NE - TBSFPPILT

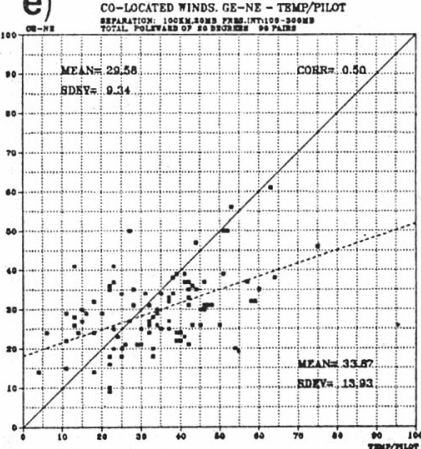

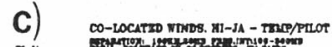

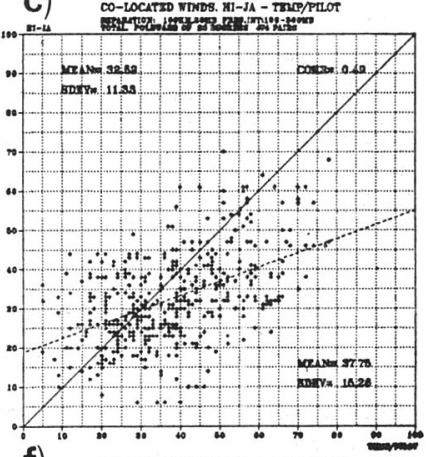

f) 1000

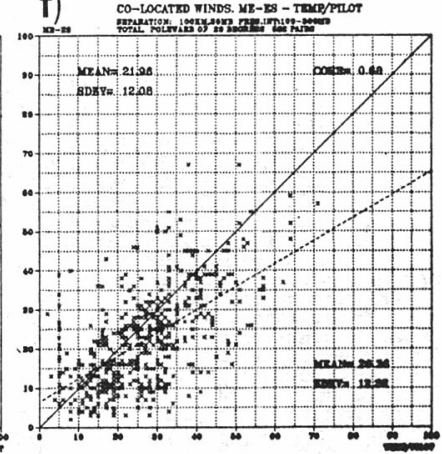

\begin{tabular}{llll|lll|} 
& & & \multicolumn{2}{c}{ TEMP/PILOT } & \\
Fig. & Dataset & Mean & S. Dev & Mean & S. Dev & Corr. \\
\hline a & GOES-IO/SSEC & 22.56 & 10.59 & 31.09 & 12.15 & 0.51 \\
b & Himawari/SSEC & 27.74 & 12.17 & 38.60 & 15.32 & 0.65 \\
c & Himawari/Japan & 32.52 & 11.33 & 37.75 & 16.26 & 0.49 \\
d & GOES-W/NESS & 26.41 & 11.10 & 31.39 & 13.27 & 0.64 \\
e & GOES-E/NESS & 29.58 & 9.34 & 33.87 & 13.93 & 0.50 \\
f & Meteosat & 21.96 & 12.06 & 26.36 & 12.32 & 0.60 \\
g all producers combined & 25.91 & 11.98 & 34.66 & 14.66 & 0.61
\end{tabular}

Fig. 8 Scatterograms of collocated SATOB data and TEMP/PILOT data for different producers. a) GOES-IO/SSEC, b) Himawari/SSEC, c) Himawari/Japan, d) GOES-W/NESS, e) GOES-E/ NESS, f) Meteosat/ESA, g) all producers combined. The table gives the means and standard deviations as well as the correlation for each system in each figure.

The dashed line is the linear regression. The time window is \pm 3 hours, separation $100 \mathrm{~km}$ and $20 \mathrm{hPa}$. Only data between $100 \mathrm{hPa}$ and $300 \mathrm{hPa}$, poleward of $20^{\circ} \mathrm{N} / \mathrm{S}$ are included. Pairs differing more than $40 \mathrm{~ms}^{-1}$ are excluded. 

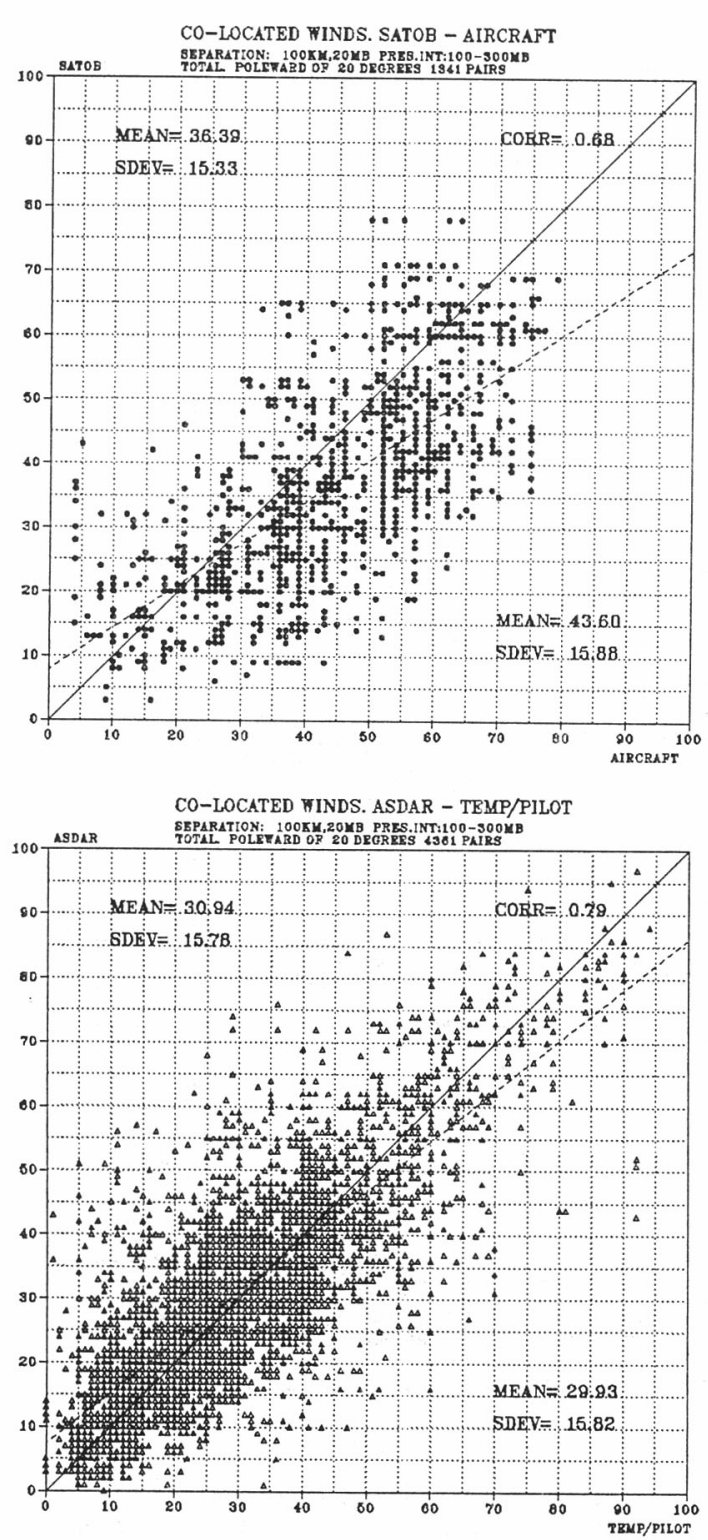

Fig. 9 As Fig. 8, but for all collocated SATOB versus aircraft data (top), and collocated ASDAR and TEMP/PILOT data (bottom). The time window is 1 hour.

izontal separation $100 \mathrm{~km}$ and the vertical separation $20 \mathrm{hPa}$. Pairs differing more than $40 \mathrm{~ms}^{-1}$ in the windvector were excluded from the scatterogram and the statistics. Only SATOBs assigned between $100 \mathrm{hPa}$ and 300 $\mathrm{hPa}$ were included.

All the subsets show large negative biases, although the sample sizes are too small for definite conclusions about the NESS produced winds. Similar results have been obtained by
M. -C. Pierrard (1985) at Meteorologie Nationale in Paris who has collected collocation statistics for Meteosat during 18 months between between August 1983 and March 1985. No significant biases were seen in the directions, although as for the speeds, the standard deviation was large. Collocated SATOB and aircraft data snow a similar behaviour, Figure 9 (top). Here the time window is 1 hour. Due to the small sample size, the statistics are not shown for the individual producers. As a comparison, Figure 9 (bottom) shows the scatter of collocated ASDAR-TEMP/ PILOT data. The ASDAR speeds, and also AIREP speeds, show hardly any bias to the TEMP/PILOT data. This is also true for direction. In the deep tropics, where observed windspeeds are much weaker, no significant biases are found in the SATOB data.

It should be pointed out that the collocation statistics were derived using the SATOB heights as assigned by the producer. The biases may thus be due either to actual underestimates of the wind speed, or systematically erroneous height assignments, or both.

\section{A calibration experiment}

The systematic, large and negative biases found in midlatitude upper troposphere zonal wind speed data from SATOB observations, raises the question whether some kind of calibration could be applied to the observed windspeeds. To test this idea, an observing system experiment was carried out.

Two parallel assimilations, control (CNTRL) and calibrated (CALIB), were run for 5 days in the beginning of January 1979. The assimilation system was identical to that used for December 1978. In the CALIB experiment, SATOB data poleward of $20^{\circ} \mathrm{N} / \mathrm{S}$ and above $600 \mathrm{hPa}$ were calibrated to remove the bias. Otherwise CNTRL and CALIB were identical. The calibration method was very simple; all reported SATOB windspeeds, in the selected areas, were modified according to the following expression

$$
\begin{gathered}
|\underline{V}|_{\text {mod }}=1.8 \times\left(|\underline{V}|_{o b s}-8.6\right) \\
\text { for }|\underline{V}|_{o b s} \geqq 20 \mathrm{~ms}^{-1}
\end{gathered}
$$

The constants were chosen from the mean 
of the two linear regression lines in the SATOB-ASDAR/AIREP and SATOB-TEMP/ PILOT collocation comparisons from December 1978.

The mean difference between all CALIB and all CNTRL analyses, Figure 10, shows the areas where the calibration has the largest effects. The impact is pronounced in areas with few other data, while the analyses are more similar in regions with ample aircraft data, for instance between the west coast of the USA and Hawaii.

The calibration reduces the bias in the observed minus first guess statistics, shown in Figure 11 for the $u$-component in areas poleward of $20^{\circ} \mathrm{N} / \mathrm{S}$ and between $100 \mathrm{hPa}$ and

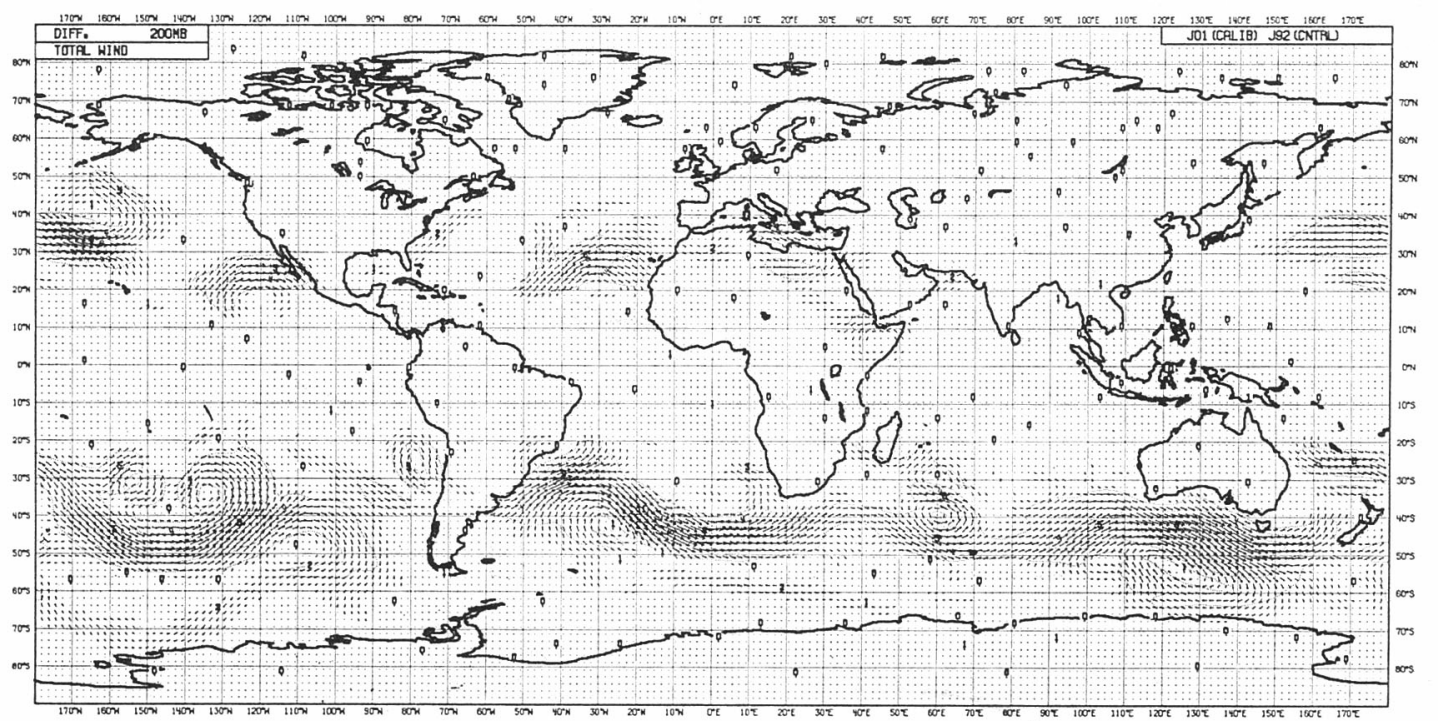

Fig. 10 Mean difference, CALIB minus CNTRL, for five days. The largest difference vector corresponds to $8 \mathrm{~ms}^{-1}$.
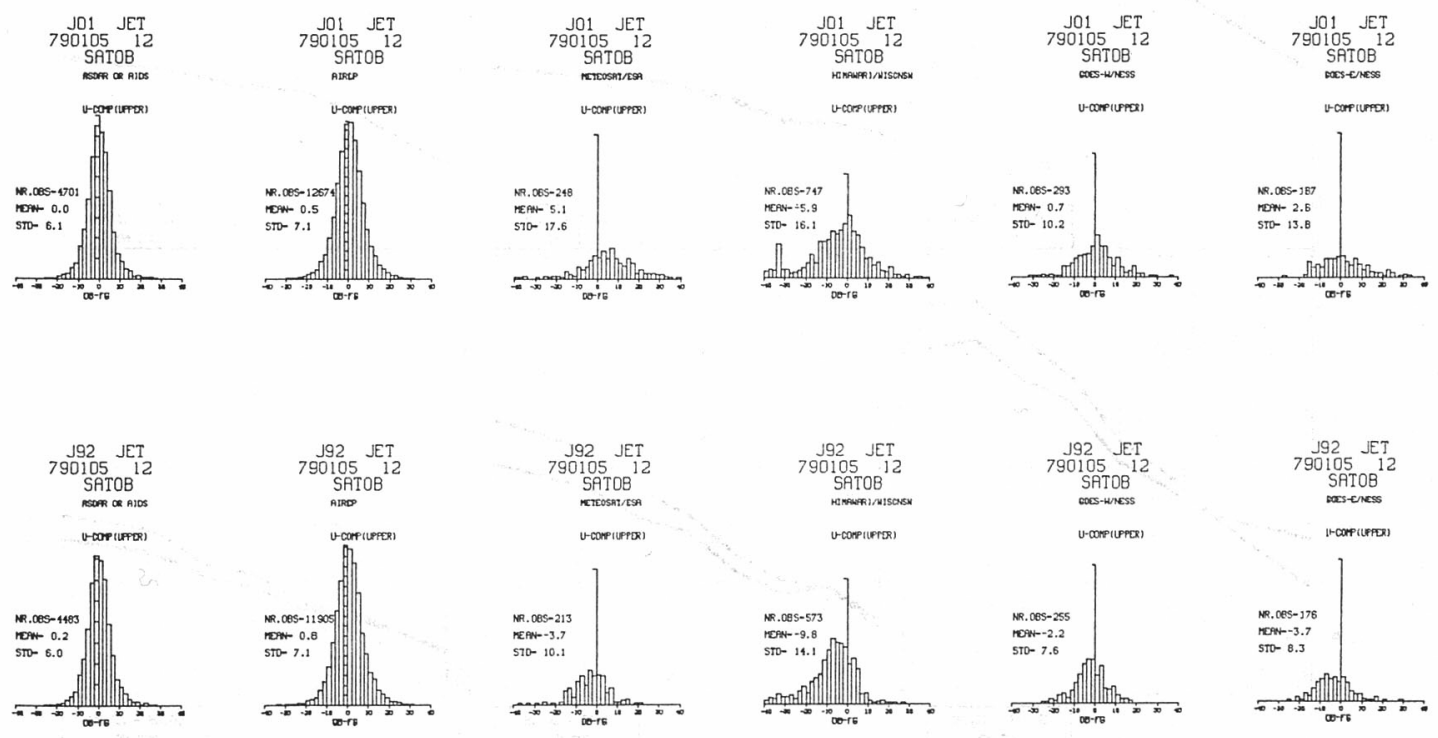

Fig. 11 Observed minus first guess windspeeds, poleward of $20^{\circ} \mathrm{N}$ and between $100 \mathrm{hPa}$ and $300 \mathrm{hPa}$. The vertical scale is shown on the central (zero) bar, in units of 100 observations. Mean and standard deviation as plotted on the graph. Top row for CALIB, bottom for CNTRL. Due to the workings of the analysis acceptance/rejection criteria, the aggregate number of observations actually used, differs between the experiments. 
$300 \mathrm{hPa}$. The mean bias in the University of Wisconsin Himawari data is reduced from $-9.8 \mathrm{~ms}^{-1}$ to $-5.9 \mathrm{~ms}^{-1}$. For Meteosat, the bias is changed from $-3.7 \mathrm{~ms}^{-1}$ to $+5.1 \mathrm{~ms}^{-1}$, thus clearly overcalibrating. This is also the case for the GOES-E and GOES-W winds from NESS. The calibration relation was based on assembled collocation statistics for all satellites and all producers. Due to the number and distribution of pairs, the Univer- sity of Wisconsin Himawari data were heavily overrepresented in the material. Since that dataset seems to suffer from the largest biases, the selected regression line is overdoing the calibration for other SATOB data.

The positive zonal bias in aircraft data found in the December assimilation, and also seen in the CNTRL statistics is reduced to some extent by the calibration. The first guess forecasts in the CALIB assimilation are

\section{RMS WIND DIFFERENCE}
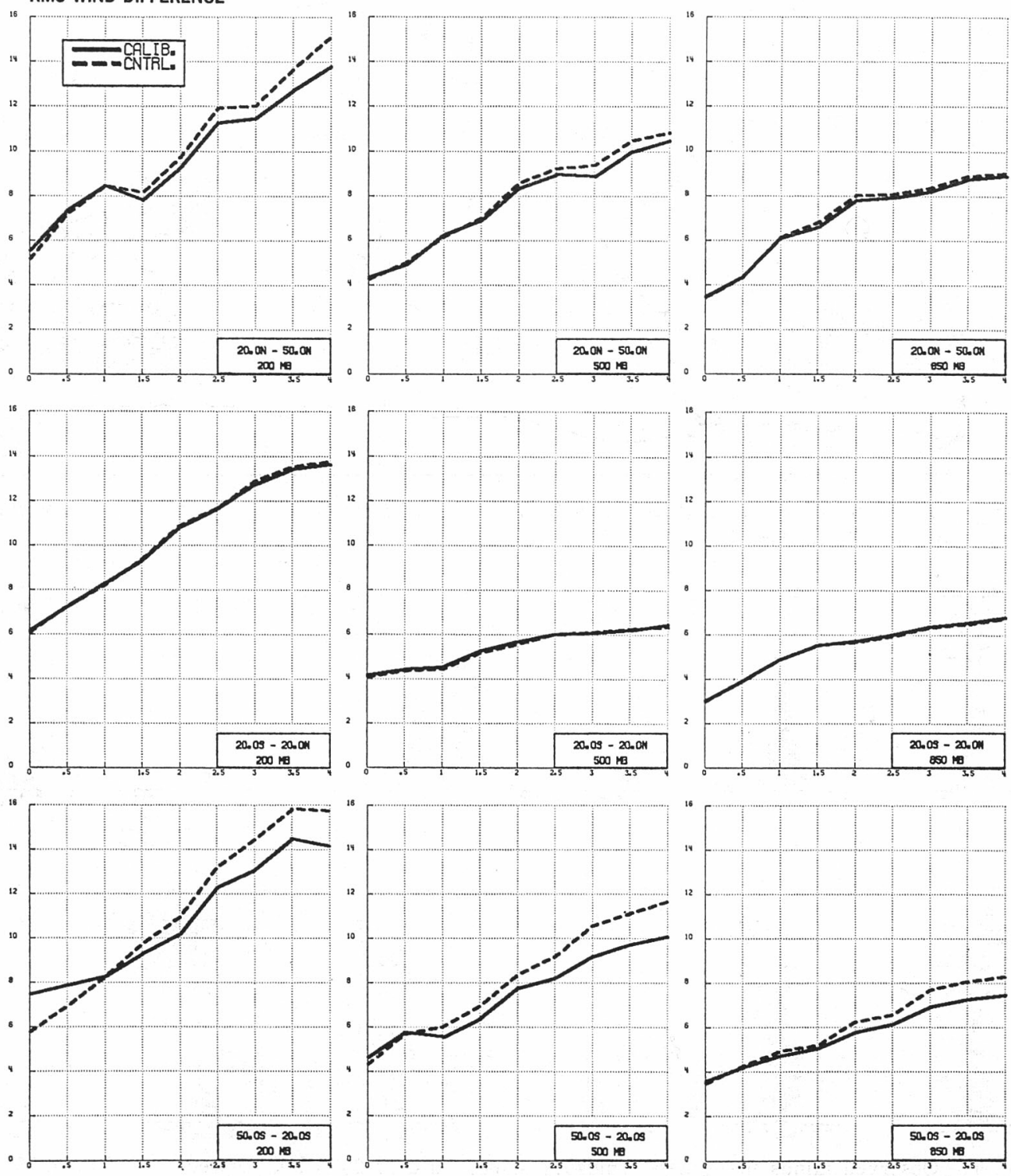

Fig. 12 Root mean square vector wind differences (absolute values in $\mathrm{ms}^{-1}$ ) between forecast and main IIIb analysis at $200 \mathrm{hPa}$ (left) $500 \mathrm{hPa}$ (central) and $850 \mathrm{hPa}$ (right). Full lines for CALIB, dashed for CNTRL. Top row $20^{\circ} \mathrm{N}$ to $50^{\circ} \mathrm{N}$, middle row $20^{\circ} \mathrm{N}$ to $20^{\circ} \mathrm{S}$ and bottom row $20^{\circ} \mathrm{S}$ to $50^{\circ} \mathrm{S}$. 
thus slightly closer to the aircraft data than the ucalibrated forecasts. Although negative biases in the $u$-component of the SATOB data are reduced by the calibration, the standard deviation of observation minus first guess is increased by a considerable amount, up to $7 \mathrm{~ms}^{-1}$ for one producer. This is an unavoidable effect of the chosen calibration method. Large standard deviations imply noisy and less reliable data. Hardly any differences were found between the two assimilations in the bias of the $v$-component. The standard deviation, on the other hand, increased in a similar fashion to that of the $u$-component.

One pair of forecasts, from CALIB and CNTRL, was made, both starting at $00 \mathrm{GMT}$, January 5, and run up to 96 hours. Experience from observing system experiments at ECMWF indicates that, due to large variations from one synoptic case to another, conclusions drawn from a single forecast pair may not be typical for a larger sample of experiments. This is particularly evident in the medium range, i.e. beyond about day 4 . It is believed, however, that for the first few days, clear differences between the forecasts should reflect a real impact of the modified observations, even if only one case is studied.

The root mean square vector difference between the forecast and verification winds is shown in Figure 12 for the latitude bands $50^{\circ}-20^{\circ} \mathrm{S}, 20^{\circ} \mathrm{S}-20^{\circ} \mathrm{N}$ and $20^{\circ}-50^{\circ} \mathrm{N}$, verified against the ECMWF Main level IIIb analyses. The initial differences between the experiment analyses and the verification are large in all areas and at all levels. This is due to the changes in assimilation systems and data coverages between experiment and verification. The initial CNTRL analysis is closer to the verification in all areas and at all levels shown, which is expected since no calibration was applied to the Main IIIb analyses. Very soon however, the CALIB forecast fits the verification better in both midlatitude bands. This is evident not only at $200 \mathrm{hPa}$ and 500 $\mathrm{hPa}$ but also at $850 \mathrm{hPa}$, below the lower limit of the calibration. The impact of the calibration is larger in the Southern than in the Northern Hemisphere analyses. The differences between the cases in the tropics are too small to be significant.

A similar impact of the wind calibration
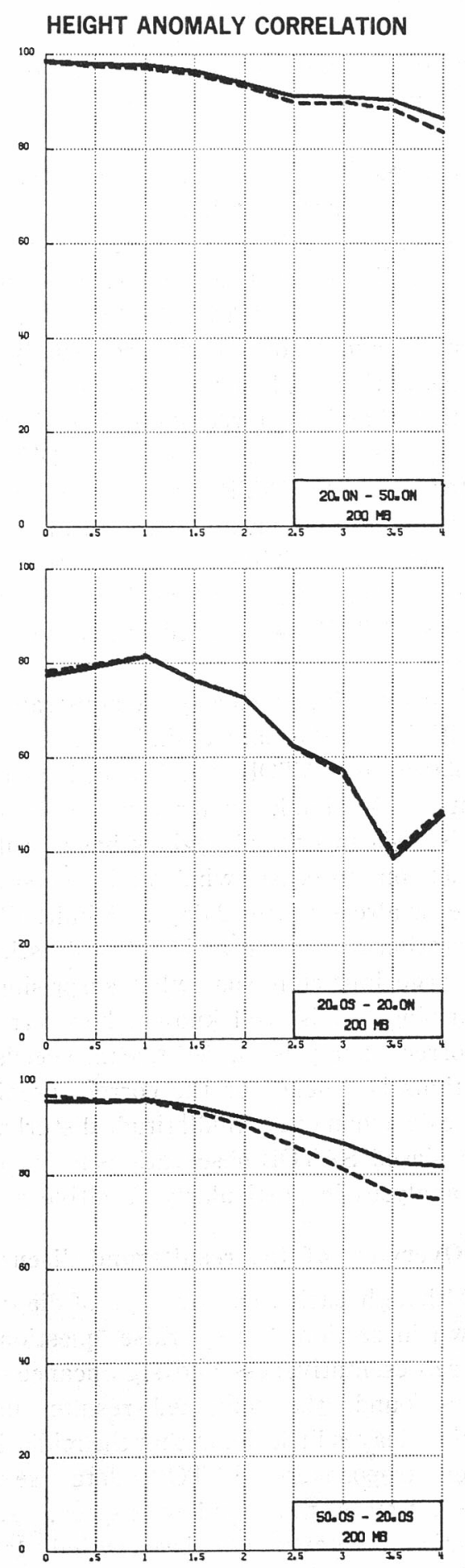

Fig. 13 Anomaly correlation of $200 \mathrm{hPa}$ geopotential in the three latitude bands $50^{\circ} \mathrm{S}-20^{\circ} \mathrm{S}$, $20^{\circ} \mathrm{S}-20^{\circ} \mathrm{N}, 20^{\circ} \mathrm{N}-50^{\circ} \mathrm{N}$. 
on the geopotential forecasts is seen in Figure 13. The good agreement between the impacts on the wind and the height fields at midlatitudes demonstrates the ability of the ECMWF data assimilation system to make use of single level wind data in a meteorologically consistent way.

A synoptic evaluation of forecast maps from the experiment indicates that in those areas where the forecasts differ appreciably, the CALIB forecast is almost always the better. Vectors of the $200 \mathrm{hPa}+48$ hour forecast error (not shown) are usually more or less antiparallel to the observed flow indicating that both forecasts underestimate jet windspeeds and wave amplitudes. Difference vectors, CALIB-CNTRL on the other hand are more often than not quasi-parallel to the observed flow. Thus the calibrated initial state reduces the underestimation of the forecast $200 \mathrm{hPa}$ windspeed and wave amplitudes.

The experiment clearly demonstrates the sensitivity of the data assimilation system to problems in SATOB wind speed measurements. A simple calibration of observed windspeeds in critical regions has a profound impact on forecast wind and geopotential patterns already after 2 days. Admittedly the calibration was crude and rather drastic, but the large impact is somewhat surprising and disturbing. It is well known, however, that a correct analysis of jet stream speeds and positions is crucial for the correct prediction of the development of midlatitude disturbances. The biased SATOB observations may corrupt the analyses in particularly sensitive areas.

\section{Overview of the results and discussion}

Although each separate type of diagnostic shown in section 2 may raise questions on the representativeness and significance of the biases found, the combined results, in our opinion, leaves little doubt that the midlatitude, upper troposphere SATOB data severely underestimate the zonal windspeed. A systematic acceptance of biased wind data is obviously serious for the climatology of the analyses, as well as the quality of forecasts run from individual analyses as shown in section 3. This is particularly critical in large parts of the Southern Hemisphere where very few independent sources of upper air wind data exist.

Several reasons for the biases may be suggested. An obvious candidate is the temperature/pressure relation used when assigning heights from measured cloud IR temperatures. This was the argument behind the height reassignment algorithm used for the Main IIIb assimilation, mentioned in the introduction. In the December data several examples were indeed found where jet stream SATOB speeds were more representative for the flow $50-100 \mathrm{hPa}$ lower down, judged from the reported temperatures and windspeeds, as compared to the first guess forecast. This would suggest that a height reassignment should be applied. Other examples, however, showed the opposite-the reported SATOB pressure seemed more consistent with the first guess than the SATOB temperature, confirming the information from SSEC (D. Wylie). From contradicting evidence it is hard to argue strongly for a height reassignment.

Another potential source of height assignment errors is the presence of thin cirrus clouds above the main visual clouds. Cloud IR temperatures may then be determined rather from such cirrus than the clouds from which the motion vectors are extracted. This problem is inherent to the data producer and can only be solved by improved retrieval methods.

A further possibility may be unrepresentativeness of the cirrus clouds as tracers of the flow. This was seen in the experiment of Kållberg et al. 1982, where jet stream level clouds over western Asia were found to be locked to orographical features rather than follow with the wind. Subsequently ECMWF decided not to use SATOB data over land. The possibility of unrepresentativeness is however not excluded over oceans either. If the clouds systematically occur on, say, the equatorward side of the jet core, as is frequently observed, the horizontal distribution of SATOB data may generate biases to the first guess. The collocation results, however, contradict such a proposal. 
Although providing invaluable information from otherwise very sparsely observed parts of the atmosphere, the SATOB data do suffer from quality problems not encountered in other data sources. The use of these data in data assimilation systems requires close monitoring and strict quality control to give maximum positive impact. Preferably some of the meteorological quality control should be made at the time of the wind extraction, using information from a high quality global forecasting system.

\subsection{Consequences for the Final IIIb assimilation}

The appreciable bias problems found in the December data made a revision of the way the data were used urgent. Although the calibration experiment showed positive impact, the method was considered rather dangerous to apply indiscriminantly. In areas with resonable coverage of other datatypes, complete elimination of SATOB data above $600 \mathrm{hPa}$ also over sea areas is a safer practice, and this was done for SATOB data from Meteosat, GOES-IO and Himawari north of $20^{\circ} \mathrm{N}$.

In the southern hemisphere, with its very low density of other types of upper air wind data, the SATOB data were deemed absolutely essential. It was thus decided to apply the calibration algorithm to Meteosat, GOES-IO and Himawari south of $20^{\circ} \mathrm{S}$. Since the small sample made it hard to draw conclusions on possible biases in GOES-E and GOES-W, we decided not to calibrate those data. This decision might be justified from the fact that winds in the GOES-E/GOES-W area are comparatively weak, and SATOB speed biases are in general proportional to the windspeed. Figure 14 summarizes the use of the SATOB

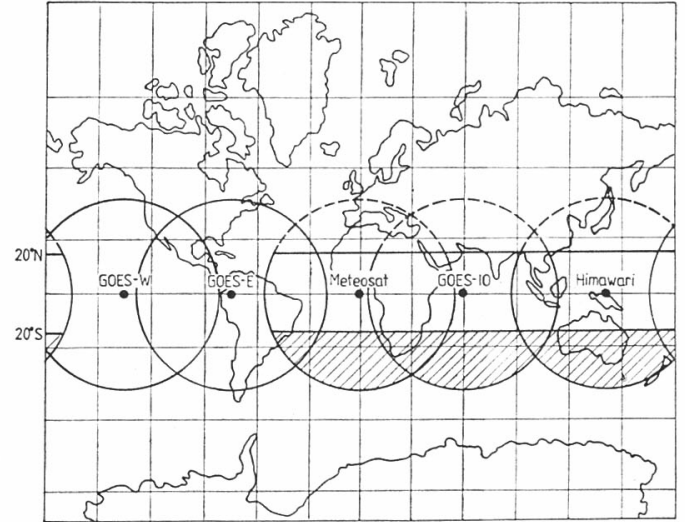

Fig. 14 Use of SATOB data in ECMWF Finall IIIb assimilation. See text.

data for the Final IIIB production. In this connexion it should also be mentioned that low level, trade wind cumulus SATOB in the Final IIb database frequently occur very close to the sea surface $(\sim 990 \mathrm{hPa})$. It was decided to move all SATOB data below $900 \mathrm{hPa}$ up to that level.

Statistics of the fit of (uncalibrated) data to the two sets of analyses for May 1979, in Table 2, show that the Final analyses are considerably closer to TEMP/PILOT and Aircraft data than the Main. This is true at all latitudes. In the tropics the SATOB data also fit the Final better than the Main, while at higher latitudes, the Final analyses are further away from these data. Whether these changes are due to the revised assimilation system or the revised treatment of SATOB is impossible to decide, most likely both factors are important. Clearly the revised observational and forecast error statistics makes the optimum interpolation draw closer to the data, and the diabatic initialization provides a more divergent and thus more realistic first guess

Table 2 Root mean square of vector wind difference, observed minus analyzed. $200 \mathrm{hPa}$, May 1979.

\begin{tabular}{|c|c|c|c|c|c|c|}
\hline & \multirow{2}{*}{$\begin{array}{c}\text { Global } \\
\text { Main }\end{array}$} & \multirow[b]{2}{*}{ Final } & \multicolumn{2}{|c|}{$20^{\circ} \mathrm{S}-20^{\circ} \mathrm{N}$} & \multicolumn{2}{|c|}{ Iets $>25 \mathrm{~ms}^{-1}$} \\
\hline & & & Main & Final & Main & Final \\
\hline TEMP/PILOT & 6.1 & 5.3 & 6.2 & 5.5 & 7.7 & 6.6 \\
\hline AIRCRAFT & 8.4 & 7.7 & 7.6 & 6.8 & 10.1 & 9.6 \\
\hline SATOB & 8.6 & 9.8 & 6.6 & 6.1 & 9.0 & 10.6 \\
\hline
\end{tabular}




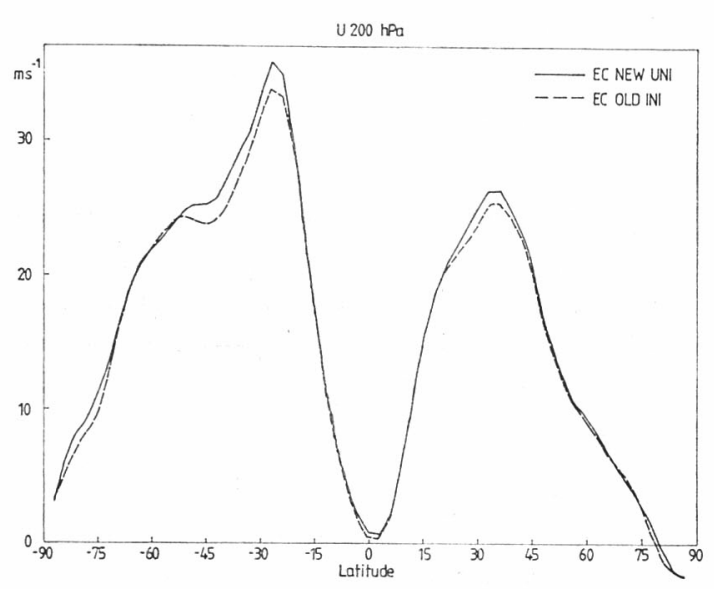

Fig. 15 Zonal mean wind at $200 \mathrm{hPa}$ for May 1979. Full line Final IIIB, dashed Main IIIB.

in the ITCZ. On the other hand, as demonstrated by the evaluation of the December data, a first guess forecast not contaminated by biased SATOB windspeeds makes it easier to achieve a consistent, and correct, analysis from high quality TEMP/PILOT and Aircraft data.

In Figure 15 the overall impact on the May 1979 monthly mean zonal windspeed is shown for the Main ECMWF IIIb and the Final ECMWF IIIb analyses. Subtropical jet maxima are stronger both in the northern (summer) hemisphere where SATOB were excluded and the southern (winter) hemisphere, where they were calibrated.

Judging from the better agreement between analyses and high quality TEMP/PILOT and Aircraft data in jetstream areas (Table 2), the ECMWF Final IIIb jetstream analyses are closer to reality than those of the Main IIIb.

\section{Acknowledgement}

It is a pleasure to acknowledge the major effort done by Sakari Uppala on the reanalysis of the FGGE SOPs, and in particular the evaluation of the May analyses in section 4 . Discussions with A. Hollingsworth and other
ECMWF staff members and visiting scientists were a constant source of inspiration. The expert typing and drafting of A. Karlsson and A. Bergstrand is much appreciated.

\section{References}

Baede, A.P.M., P. Kållberg and S. Uppala, 1985 : Impact of aircraft wind data on ECMWF analyses and forecasts during the FGGE period, 8-19 November 1979. ECMWF Tech. Rep., 47, 85 pp.

Delsol, F., 1985: Monitoring the availability and the quality of observations at ECMWF. ECMWF Workshop on the Use and Quality Control of Meteorological Observatiosn, 8-9 November 1984, Reading, U. K., 55-89.

Hollingsworth, A. and P. Lönnberg, 1986: The statistical structure of short range forecast errors as determined from radiosonde data. Part I : The wind field. Tellus, 38A, 111-136.

, A.C. Lorenc, M. S. Tracton, K. Arpe, C. G. Cats, S. Uppala and P. Kållberg, 1985: The response of numerical weather prediction systems to FGGE II-b data, Part I: Analyses. Quart. J. Roy. Met. Soc., 111, 1-66.

Julian, P., 1980: An evaluation of the FGGE tropical observing system. International Conference on Preliminary FGGE Data Analysis and Results, Bergen, Norway, 23-27 June 1980, WMO/GARP, Geneva, 239-296.

Kållberg, P., S. Uppala, N. Gustafsson, J. Pailleux, 1982: The impact of cloud track wind data on global analyses and medium range forecasts. ECMWF Tech. Rep., 34, 60 pp.

Lönnberg, P. and A. Hollingsworth, 1986: The statistical structure of short range forecast errors as determined from radiosonde data. Part II : The covariance of height and wind errors. Tellus, 38A, 137-161.

Pierrard, M.-C., 1985: Intercomparison between cloud track winds and radiosonde winds. Proceedings of the Meteosat user conference-Rome, May 1985, ESA.

Shaw, D., P. Lönnberg and A. Hollingsworth, 1984 : The 1984 revision of the ECMWF analysis system. ECMWF Tech. Memo., 92, 69 pp.

Uppala, S., 1986: The assimilation of the final level IIB dataset at ECMWF, Part I. Proceedings of the "National Conference on Scientific Results of the First GARP Global Experiment". Miami, USA. Jan 14-17 1986. 